\title{
Avaliação econômica de projetos de sistemas agroflorestais
}

\author{
Diogo Nepomuceno Cosenza ${ }^{1 *}$, Silvio Nolasco de Oliveira Neto ${ }^{1}$, Laércio Antônio Gonçalves Jacovine ${ }^{1}$, Caroline Ribeiro Rodrigues ${ }^{1}$, \\ Rafael Rode ${ }^{2}$, Vicente Paulo Soares ${ }^{1}$, Helio Garcia Leite ${ }^{1}$
}

${ }^{1}$ Universidade Federal de Viçosa, Av. Purdue, s/no , CEP 36570-900, Viçosa, MG, Brasil

${ }^{2}$ Universidade Federal do Oeste do Pará, Rua Vera Paz s/nº, CEP 68035-110, Santarém, PA, Brasil

"Autor correspondente:

dncosenza@gmail.com

Termos para indexação:

Análise econômica

Sistemas agroflorestais

Gestão de projetos

Index terms:

Economic analysis

Agroforestry systems

Project management

Histórico do artigo:

Recebido em 07/04/2016

Aprovado em 05/12/2016

Publicado em 30/12/2016

doi: $10.4336 / 2016 . p f b .36 .88 .1218$

\begin{abstract}
Resumo - Por se tratar de uma atividade complexa, os estudos de viabilidade econômica de sistemas agroflorestais (SAFs) exigem maior esforço para avaliação. Dentre os motivos estão a maior quantidade de elementos a serem considerados, a necessidade de prever os efeitos das interações entre as diferentes espécies consorciadas e a dificuldade de valorar os benefícios ambientais do sistema. Dessa forma, o objetivo deste trabalho foi analisar e sintetizar os principais métodos de avaliação econômica descritos na literatura. Através dele é possível determinar quais itens devem ser computados na análise e como atribuir valores a eles para definir as principais receitas e custos do projeto. Ainda, podem ser traçados os principais métodos de análise econômica e de comparação de resultados. Por fim, entende-se que existem dificuldades na valoração de muitos benefícios que os SAFs proporcionam, mas estas podem ser contornadas pelas metodologias apresentadas. Além disso, criou-se a necessidade de promover os benefícios ambientais (externalidades) do sistema, a fim de valorizar os seus serviços frente ao mercado.
\end{abstract}

\section{Economic evaluation of agroforestry projects}

\begin{abstract}
Studies of agroforestry systems (AFSs) economic feasibility require more efforts to evaluate due to the complexity of the activity. Among the reasons are the greatest number of elements to be considered, the need to provide effects of interactions between intercropped species and the difficulty of valuing environmental benefits of the system. Thus, the aim of this study was to analyze and summarize the main economic valuation methods described in the literature. It was possible to determine which items must be counted in the analysis and how to assign value to them to define the main incomes and project costs. Also, the main methods of economic analysis were drawn and we discussed how to compare their results. Finally, it was understood that there are difficulties in evaluation of others AFSs benefits, but they can be overcome by presented methodologies. In addition, it was created the need to promote environmental benefits of the system (externalities), in order to enhance their market values.
\end{abstract}

\section{Introdução}

Apesar de ser uma prática secular, os sistemas agroflorestais (SAFs) têm recebido atenção nas últimas décadas, como forma alternativa de produção sustentável. Os trabalhos publicados no final do século
XX contribuíram para consolidar a agrossilvicultura como um nicho próprio de estudo, assim como é a agricultura e a silvicultura, dado à sua complexidade $\mathrm{e}$ relevância socioambiental (Nair, 1997).

A sua principal característica, e que a distingue das demais práticas convencionais, é a possibilidade de se 
aproveitar das interações entre as diferentes culturas agrícolas, utilizadas simultaneamente no sistema, para potencializar a produção de bens e/ou de algum serviço ambiental (Rao et al., 1997; García-Barrios \& Ong, 2004; Batish et al., 2008). Como consequência, cada SAF passa a ter a sua peculiaridade, pois pode apresentar configurações diferenciadas de manejo e das espécies utilizadas para atingir objetivos diversificados (Nair, 1993; Oliveira Neto et al., 2010).

Por conta dessa variabilidade, a formulação de projetos de implantação de SAFs deve ser criteriosa, elaborada a partir de diagnósticos locais e das necessidades das partes interessadas. Dois métodos bastante utilizados nesta etapa são o diagnóstico e desenho (D\&D), descrito em Raintree (1986), e o diagnóstico rural participativo (DRP), muito utilizado em associação com o D\&D por extensionistas rurais (Vivan, 2000; Faria, 2013). Esses métodos auxiliam a identificação de demandas dos pesquisadores, produtores e/ou investidores, bem como o delineamento do desenho do sistema que melhor se adequa aos objetivos propostos (Cardoso et al., 2001)

Para a formulação de projetos em si, Rezende \& Oliveira (2013) recomendam que alguns pontos básicos devem ser especificados além dos seus objetivos, como qual ou quais produtos que se desejam produzir, o quanto destes produtos serão necessários e qual será efetivamente a produção na condição de sua instalação. Usa-se o mesmo raciocínio quando o objetivo é a produção de serviços, o que traria a necessidade de especificar quais seriam os benefícios contemplados, bem como a quantidade e/ou qualidade deste benefício que seria produzido pela execução do projeto na forma em que foi delineado.

Desta maneira, o projeto deverá considerar todos os fatores envolvidos no estabelecimento do SAF para justificar a sua implantação. Tal justificativa se dará através das expectativas de produção e de renda, dos benefícios gerados e da previsão dos recursos a serem utilizados para sua implantação e condução (Rezende \& Oliveira, 2013). A partir deste projeto é que serão elaborados os estudos de viabilidade, os quais permitirão visualizar a capacidade do impreendimento de ser factível do ponto de vista social, político, econômico, financeiro ou mesmo ambiental, e auxiliarão também as partes interessadas na tomada de decisão sobre a implantação ou não do SAF.

Estes estudos de viabilidade, sobretudo os de ordem econômico financeiro, foco deste trabalho, se diferenciam dos demais projetos agrícolas, pecuários ou florestais, por terem mais elementos a serem computados, por gerar benefícios que não são facilmente quantificáveis e, não raro, pela imprevisibilidade dos resultados das interações entre as culturas para se calcular os rendimentos (Torquebiau \& Penot, 2006; Thompson \& George, 2009). Este último aspecto consiste então em um empecilho nesta análise, pois as informações sobre a produtividade dos diversos consórcios, num dado arranjo em um ambiente específico, podem não estar disponíveis aos técnicos e pesquisadores para elaboração de seus projetos.

Estas peculiaridades associadas à falta de informação podem dificultar a formulação do projeto do SAF, bem como a sua análise econômica, por ser difícil determinar uma faixa segura de produção das culturas no sistema. Como consequência, os riscos assumidos no momento da decisão sobre a sua implantação podem ser maiores, principalmente quando a questão financeira ou econômica for um fator limitante do projeto.

Entretanto, o fato de não haver publicações que tragam as informações desejadas, não significa necessariamente o impedimento da elaboração do projeto. Neste caso, é necessário realizar uma análise econômica mais abrangente, capaz de prever possíveis variações de mercado e de produtividade, para minimizar os erros de avaliação.

Sendo assim, este trabalho tem como objetivo sintetizar e analisar diferentes métodos de avaliação econômica de sistemas agroflorestais. Além disso, o trabalho espera ser útil como leitura inicial e prática para auxiliar técnicos e pesquisadores que intencionam avaliar ou construir este tipo de projeto, sem a intenção de exaurir os trabalhos publicados sobre o assunto. Para isso, será feita uma abordagem inicial dos principais itens a serem computados na análise. Em seguida, serão descritos os principais métodos de avaliação econômica de projetos e as principais formas de valoração de SAFs. Por fim, serão discutidos os métodos de análise de sensibilidade do SAF e as alternativas para se comparar os resultados da avaliação econômica.

\section{O que computar na análise}

Conforme apresentado por Rezende \& Oliveira (2013), a avaliação econômica de um projeto se baseia no seu fluxo de caixa, que seria o somatório das diferenças entre receitas e custos ao longo da vida útil do empreendimento. Porém, a definição destes números 
só será possível após a determinação do sistema a ser implantado.

Uma técnica alternativa ao diagnóstico e desenho (D\&D) e ao diagnóstico rural participativo (DRP) é a do $5 \mathrm{~W}-2 \mathrm{H}$, comumente utilizada no ambiente corporativo para identificação de problemas. Neste método são propostas sete perguntas básicas sobre as demandas que se quer atender. Uma descrição de como aplicar esse método no meio rural, mas precisamente no meio florestal, pode ser encontrado no trabalho de Trindade et al. (2007). Segundo os autores, dessas perguntas podem derivar outras relacionadas, o que tornaria o objetivo mais claro e específico, facilitando a sua realização.

A primeira delas é o quê (What?), onde se busca responder qual é o problema ou a demanda a ser atendida; o que deve ser feito ou o que já está sendo feito para que justifique a implantação do SAF. A outra pergunta é onde (Where?) se deve realizar o empreendimento; onde já está sendo feito e onde mais se pode fazer. A terceira é para responder quem (Who?) são as partes envolvidas com o projeto; se há mais alguém que pode participar; quem são os responsáveis; quem poderia e quem deverá realizá-lo; para quem os produtos ou serviços serão destinados. Na quarta pergunta a intensão é saber quando (When?) o problema ocorre ou quando um fato comum poderá se torna um problema; quando se deseja obter os resultados e quando eles podem ser obtidos, sejam eles na forma de bens e/ou de serviços; quando o sistema pode e quando ele deverá ser implantado, substituído, alterado ou mesmo removido da área. A quinta pergunda, por que (Why?), se destina a saber os motivos que levariam à adoção do SAF; por que ele se tornou necessário ou oportuno; por que um dado problema está ocorrendo na área ou com as partes envolvidas, ou por que um simples fato se tornou um problema; qual o motivo de se implantar no momento em que se quer implantar e da maneira que se deseja implantar. A sexta questão auxiliará a definir como (How?) se deve proceder para alcançar os objetivos; qual metodologia utilizar; qual desenho pode atender melhor as partes interessadas; qual seriam as vantagens e desvantagens do desenho proposto; se há algum método em desenvolvimento na área, como ele está sendo feito ou como proceder para que ele melhore; como utilizar os recursos da melhor maneira possível ou como obtê-los. Por último, as perguntas devem ser feitas para descobrir quanto (How much?) será necessário despender para que o projeto seja executado e os objetivos alcançados; quanto será o rendimento, ou quanto ele pode render; quanto está custando para executá-lo no momento atual, ou quanto seria num momento posterior ou se for implantado em outro local; qual o custo atual de não se implantar o SAF; quanto se tem de capital disponível para que o projeto seja executado.

Enfim, qualquer outra questão referente ao assunto será bem vinda para conferir maior segurança ao projeto ou sistema proposto. A questão "quanto", no entanto, somente será respondida a partir do momento em que se souber quais itens deverão ser inserido na análise.

Com relação aos custos, Thompson \& George (2009) sugerem ignorar da análise financeira aqueles ocorridos anteriormente à decisão sobre o projeto. Segundo os autores, podem ser incluídos aqueles que variam com a produção (custos variáveis): relacionados à implantação, colheita, manutenção, entre outras; os custos gerais que estejam indiretamente envolvidos na atividade agroflorestal, como as despesas administrativas ou com trabalhos adicionais na propriedade; os custos de investimento, envolvidos com compra e locação de terras, maquinário, financiamentos e depreciação; e o custo de capital, que é o valor que se deixa de ganhar por não se adotar outra alternativa de investimento, como a monocultura e investimentos bancários relacionados com as taxas de juros.

Um custo muitas vezes negligenciado nas análises econômicas é o referente ao valor da terra, que pode ser o preço de aquisição da área corrigido pela taxa de juros ou o valor pago pelo aluguel da área a ser implantada (Silva et al., 2005). Rezende \& Oliveira (2013) salientam que apesar de este custo reduzir o valor dos indicadores, a não inclusão dele seria antiético, pois se trata de um custo de oportunidade que estará sempre presente para o investidor.

Neste conceito, Faria (2013) incluiu este custo para avaliar dois sistemas agroflorestais e um monocultivo para recuperação e manutenção de pastagens. O autor se baseou no valor pago pela propriedade se ela fosse arrendada para uma indústria canavieira. Dessa forma, verificou-se que o valor da terra foi um dos fatores chave na análise econômica, correspondendo de $22 \%$ a $43 \%$ dos custos totais dos sistemas avaliados.

Outro custo importante que pode ser incluído é a remuneração dos próprios produtores, a qual poderá ser definida pela jornada de trabalho ou por um valor que se queira receber ao longo do período do planejamento (Thompson \& George, 2009). No entanto, os produtores 
deverão utilizar empréstimos caso não haja capital disponível para suprir suas necessidades financeiras ao longo da duração do projeto, o que geraria um custo adicional em decorrência dos juros. A definição desta remuneração tem um caráter subjetivo, pois irá variar conforme os anceios dos produtores. Além disso, é possível que os SAFs sejam mais intensivos em mão de obra, uma vez que estes exigem mais tratos culturais que os sistemas convencionais (Lyngbæk et al., 2001; Souza et al., 2012). Mesmo assim, uma maneira prática de se obter este valor seria se basear no custo de oportunidade do tempo, isto é, considerar o valor pago pela diária praticado na região multiplicado pelo tempo despendido nas atividades do SAF. A participação desta mão de obra nos custos totais pode ser obtida pela razão entre a soma destas diárias (acumuladas em cada mês) e os demais custos do SAF, ambos corrigidos para o tempo presente.

No que tange às receitas, estas serão definidas pela quantidade de bens produzidos no sistema, fruto das interações ou não, sendo multiplicados pelo seus respectivos preços (Thompson \& George, 2009). Também podem ser incluídas as receitas geradas por algum pagamento por serviço ambiental (PSA), como crédito de carbono (Müller et al., 2009) ou provenientes de programas públicos que permitam internalizar os benefícios ambientais gerados no SAF (Alavalapati et al., 2004; Wunder et al., 2009; Costa et al., 2013).

Naturalmente, espera-se que a diversidade de itens seja maior quanto mais complexo for o sistema, uma vez que os produtos também poderão ser mais diversificados (Santos et al., 2002; Bentes-Gama et al., 2005). Neste caso, uma forma que facilitaria a contabilização destes itens seria separá-los por estrato do sistema. Por exemplo, nos sistemas cujos estratos são bem definidos, semelhantes ao taungya (em que há cultivo de culturas anuais nos primeiros anos da cultura florestal) ou cultivo em aleias, caberia separar o fluxo de caixa entre o componente arbóreo e o componente agrícola, buscando considerar as consequências econômicas das interações, sempre que possível.

Em sistemas multiestratos essa separação se tornaria menos evidente e, muitas vezes, alguns produtos são para uso dos proprietários (Torquebiau \& Penot, 2006). Nestes sistemas podem-se contabilizar as receitas e os custos dos produtos comercializáveis, separando-os por utilidade, como aqueles destinados à alimentação, para fins medicinais, ou ao suprimento de materiais, como madeira, óleos, borracha, sementes e resinas.
Quando uma dada quantidade de produtos é destinada à subsistência dos produtores ou para a própria fazenda, é sugerido estimar o consumo anual destes bens e computar suas receitas e custos no fluxo de caixa do SAF como se fossem vendidos normalmente (Nair, 1997; Torquebiau \& Penot, 2006). Dessa maneira, o lucro referente a estes bens representaria o valor poupado por não ser necessário comprá-los no mercado convencional. Ainda, podem ser considerados bens substitutos, quando o produtor troca diretamente parte de sua produção com outros proprietário ou em feiras livres. O raciocínio de cálculo dos custos é análogo ao anterior, considerando que na relação de troca os produtos de interesse normalmente apresentam maior valor agregado.

\section{Métodos de análise econômica}

Como apresentado por Rezende \& Oliveira (2013), só faz sentido analisar um investimento se considerarmos o seu horizonte de planejamento, que seria o tempo estimado de duração do empreendimento, podendo ser finito ou infinito. No caso de sistemas arborizados, este horizonte tenderá a ser longo ou mesmo infinito, de forma a abranger os custos e/ou receitas anuais referentes ao componente arbóreo.

Dessa maneira, os métodos de avaliação mais indicados seriam aqueles que levassem em consideração a variação do capital ao longo do tempo, ou seja, que fossem atualizados por uma taxa de desconto referente a uma alternativa de investimento.

A escolha desta taxa será, portanto, baseada no contexto econômico do país, sendo comum encontrar trabalhos utilizando descontos de $3 \%$ a $15 \%$, ressaltando que taxas maiores favorecem alternativas de curto prazo (Rezende \& Oliveira, 2013), o que tornaria a análise mais conservadora.

Dentre os métodos de análise econômica, está o valor presente líquido (VPL) para horizontes finitos e infinitos (equações 1 e 2), que seria a diferença entre o somatório das receitas e dos custos corrigidos para o tempo atual (Silva \& Fontes, 2005).

$$
\begin{gathered}
V P L_{\text {Finito }}=\sum^{n} R_{t} *(1+i)^{-t} \boxminus \sum^{n} C_{t} *(1+i)^{-t} \\
V P L_{\text {Infinito }}=\frac{V P L_{\text {finito }} *(1+i)^{t}}{\left[(1+i)^{t}-1\right]}
\end{gathered}
$$

Em que: $R_{t}=$ receita total ao final do ano ou período de tempo $t ; C_{t}=$ custo total ao final do ano ou período de tempo $t ; i=$ taxa de juros; $n=$ duração do projeto em anos; $V P L_{\text {finito }}$ 
$=$ valor presente líquido de um ciclo de cultivo; $V P L_{\text {infinito }}=$ valor presente líquido de um ciclo de cultivo que se repete perpetuamente a cada $t$ anos.

O uso do VPL finito é sem dúvida o indicador mais encontrado nas publicações. Santos et al. (2002) fizeram o uso simultâneo deste com o VPL infinito para fazer análise econômica de quatro projetos de SAFs. Em seu trabalho os autores calcularam isoladamente o VPL infinito para as culturas perenes (ex. açaí e mogno) e o VPL finito para as culturas anuais ou que não se repetem dentro do sistema (ex. arroz e mandioca). Assim, o valor presente total do SAF foi obtido pela soma dos dois tipos de VPLs, tornando a análise mais precisa. O projeto será viável economicamente se o VPL total for positivo, para as duas formas de cálculo.

Outro método é através do benefício (custo) periódico equivalente $(\mathrm{B}(\mathrm{C}) \mathrm{PE})$, que pode ser calculado pela equação 3.

$$
B(C) P E=\frac{V P L *\left[(1+i)^{t}-1\right] *(1+i)^{n t}}{(1+i)^{n t}-1}
$$

Em que: $B(C) P E=$ benefício (custo) periódico equivalente; $V P L=$ valor presente líquido; $i=$ taxa de juros; $t=$ número de períodos de capitalização; $n=$ duração do projeto em anos.

$\mathrm{O} \mathrm{B}(\mathrm{C}) \mathrm{PE}$ considera o tamanho dos projetos em análise e representaria o fluxo de caixa líquido constante no horizonte de planejamento, podendo também ser utilizado para comparar projetos de diferentes durações (Silva et al., 2005; Rezende \& Oliveira, 2013). A sua viabilidade econômica será determinada se o $\mathrm{B}(\mathrm{C}) \mathrm{PE}$ for positivo.

A fórmula do $\mathrm{B}(\mathrm{C}) \mathrm{PE}$ pode ser simplificada quando a duração do projeto $(n)$ for anual e igual ao período de captalização $(t)$ (equação 4 ). Neste caso, o VPL fica anualizado e é chamado de valor anual equivalente (VAE), indicando a viabilidade econômica do projeto se apresentar valor positivo (Silva \& Fontes, 2005).

$$
V A E=\frac{V P L * i}{1-(1+i)^{-n}}
$$

Em que: $V A E=$ valor anual equivalente; $V P L=$ valor presente líquido; $i=$ taxa de juros; $n=$ duração do projeto em anos.

A razão entre benefício e custo $(B / C)$ também é um método muito utilizado por trazer ao momento presente a relação entre os rendimentos e as despesas do projeto (equação 5).

$$
B / C=\frac{\sum_{t=0}^{n} R_{t} *(1+i)^{-t}}{\sum_{t=0}^{n} C_{t} *(1+i)^{-t}}
$$

Em que: $B / C=$ razão benefício custo; $R_{t}=$ receita total ao final do ano ou período de tempo $t ; C_{t}=$ custo total ao final do ano ou período de tempo $t ; i=$ taxa de juros; $n=$ duração do projeto em anos.

Assim, o valor encontrado representaria a quantidade de benefício gerado para cada unidade de custo e, no caso de comparações entre dois ou mais projetos, será mais vantajoso aquele que apresentar maior razão (Rezende \& Oliveira, 2013).

A viabilidade do projeto também pode ser avaliada pela taxa interna de retorno (TIR), que seria a taxa anual que retorna o capital investido ou a taxa que torna o $\mathrm{B} / \mathrm{C}=1$ (Rezende \& Oliveira, 2013), sendo calculado isolando-se a taxa e resolvendo a equação polinomial, facilmente solucionada em planilhas eletrônicas (equação 6).

$$
\sum_{t=0}^{n} R_{t} *(1+T I R)^{-t}-\sum_{t=0}^{n} C_{t} *(1+T I R)^{-t}=0(6)
$$

Em que: $T I R=$ taxa interna de retorno; $R_{t}=$ receita total ao final do ano ou período de tempo $t ; C_{t}=$ custo total ao final do ano ou período de tempo $t ; i=$ taxa de juros; $n=$ duração do projeto em anos.

Assim, o projeto será mais viável quanto maior a sua TIR, ou se esta taxa foi maior que a taxa de desconto da alternativa de investimento, também chamada de taxa mínima de atratividade (Silva et al., 2005). Cabe ressaltar que os métodos da TIR e da razão benefício custo não consideram a dimensão dos investimentos e por isso não é aconselhavel utilizá-los para comparar projetos muito distintos em temos de horizonte de planejamento ou do capital investido. Neste caso, Rezende \& Oliveira (2013) recomendam o uso destes dois métodos para avaliar o efeito econômico de pequenas variações no projeto, como local de implantação, adoção de diferentes tratos culturais ou espacialização de plantas de mesma espécie.

Como mencionado anteriormente, o custo da terra é geralmente negligenciado na análise econômica. Neste caso, o método de Faustmann do valor esperado da terra (VET) ou valor de expectativa do solo (VES) possui fórmula análoga ao VPL infinito, com a diferença de a receita líquida perpétua $(\mathrm{Rt}-\mathrm{Ct})$ ser calculada 
excluindo-se o custo da terra. O método é considerado de aplicação única na área florestal, não havendo referência a ele nos livros de economia como apontado por Rezende \& Oliveria (2013). Este mesmos autores trazem duas restrições importantes quanto ao uso do método, e que não são mencionadas na literatura: 1) o fluxo de caixa será o mesmo em perpetuidade, o que significa que será cultivada sempre a mesma espécie, para mesma finalidade, com preços constantes ao longo do tempo; 2) a terra só tem valor para a produção de madeira. Assim, a atividade agroflorestal é considerada um sistema dinâmico, pois as culturas, principamente as anuais, podem ser trocadas e o componente florestal e produtos agrícolas também podem sofrer constantes alterações, tornando dificíl determinar o VET com seu conceito clássico, como um método de avaliação dos SAFs.

Em caso de pequenas propriedades familiares, pode-se utilizar a remuneração de mão de obra familiar (Alves et al., 2015), calculada pela equação 7 .

$$
R M O F=\frac{R T F}{D T} \quad \text { e } \quad R T F=R B-C T
$$

Em que: $R M O F=$ remuneração de mão de obra familiar; $R B=$ renda bruta; $C T=$ custos totais, desconsiderando os custos de mão de obra; $R T F=$ renda do trabalho familiar; $D T=$ número de dias de trabalho.

O RMOF deve então ser obtido levando-se em consideração todo o horizonte de planejamento. Além disso, como apresentado por Alves et al. (2015), com sua aplicação é possível estimar o rendimento médio de um dia de trabalho da família. Como exemplo, estes mesmos autores utilizaram este indicador, juntamente com o VPL e o B(C)PE, para avaliar a rentabilidade da integração entre as culturas do cafeeiro e da bananeira por 24 meses na cidade de Araponga, MG, baseando-se em uma taxa de juros de $0,7 \%$ ao mês e preço de mão de obra diária de $\mathrm{R} \$ 35,00$ praticado na região, durante 130 dias. Ao fim da análise, eles verificaram pelo VPL que o sistema apresentou um lucro de $\mathrm{R} \$ 6.375,01$ após os dois anos, e um benefício mensal dado pelo $\mathrm{B}(\mathrm{C})$ $\mathrm{PE}$ de $\mathrm{R} \$ 289,49$. Ainda, a RMOF calculada foi de R\$ 91,65 ao dia, significando que o sistema geraria uma receita mensal muito maior do que se os proprietários decidissem vender a sua mão de obra para o mercado. Dessa maneira, sendo este rendimento maior que o valor pago pela mão de obra da região, para todos os trabalhadores da família, o projeto foi considerado economicamente viável.

\section{Valoração da produção}

Talvez uma das principais dificuldades no planejamento dos SAFs sejam quantificar ou valorar aquilo que será produzido, seja bens ou serviços. Este fato é tratado por Torquebiau \& Penot (2006) como uma das desvantagens destes sistemas em relação à monocultura convencional. Os autores salientam que além de serem sistemas multiobjetivos, eles possuem benefícios ecológicos ainda não internalizáveis e atributos biológicos sem valor de mercado, como a redução de riscos de produção perante as alterações climáticas ou melhoria das condições de solo. Mesmo assim, diversos benefícios são passíveis de quantificação desde que analisados da maneira correta.

Com relação aos produtos cultivados, um método simples de valoração seria se basear nos preços atualmente praticados no mercado, referentes às quantidades produzidas, por unidade, peso ou volume (Nair, 1997; Faria, 2013). No entanto, deve-se ter o cuidado ao elaborar o projeto para pesquisar se os produtores venderão os seus produtos diretamente para o consumidor final ou se para algum intermediário, pois neste último caso haveria uma redução considerável do preço da mercadoria em detrimento do lucro do revendedor. Este método parte do princípio de que não devem haver alterações significativas na qualidade dos produtos a ponto de alterar o seu preço. Entretanto, em havendo garantia de mercado diferenciado para os produtos provenientes do sistema, como ocorre com os alimentos orgânicos, estes preços poderiam então ser utilizados e contribuiriam para a viabilidade do projeto (Torquebiau \& Penot, 2006).

Para quantificar a produção serão necessários mais esforços, pois as variações na produção em decorrência das interações dos SAFs, ou mesmo as alterações de preços de mercado e os juros, podem afetar fortemente a viabilidade do projeto e por isso devem ser levadas em consideração (Souza et al., 2007).

Neste caso, é prudente que se busque na literatura os estudos que tenham objetivos semelhantes com os dos que se queira implantar ou que se estabelaça projetos piloto a fim de se verificar o potencial do sistema para uma dada área (Raintree, 1986). Com isso, haverá maior segurança sobre os resultados esperados na implantação do sistema, uma vez que o projeto será embasado na metodologia científica ou de resultados já conhecidos.

Do contrário, considerar a produção similar à do monocultivo para cada uma das espécies utilizadas pode ser uma alternativa, desde que levada em consideração a 
produção relativa ao número de indivíduos por hectare da respectiva espécie utilizada no sistema (BentesGama et al., 2005). Como exemplo, pode-se utilizar a produtividade média por planta de uma determinada espécie ou por unidade de área, se for o caso de gramíneas. Dessa forma, ao se multiplicar este valor pela quantidade ou área de indivíduos da espécie a ser utilizada, será possível simular a sua produtividade no SAF.

Nos casos que envolvem produção de madeira, a análise pode se tornar mais complexa do que para as culturas de ciclo curto. Este fato se dá uma vez que a determinação de sua idade de corte ou nível de desbaste e, consequentemente, o volume a ser produzido, será em função da análise econômica do componente arbóreo (Souza et al., 2007; Campos \& Leite, 2013). Além disso, vários estudos destacam a participação da produção de madeira na rentabilidade dos SAFs, sendo mais importante no sistema quanto maior o seu valor agregado (Dubè et al., 2000; Souza, 2005; Coelho Júnior et al., 2008; Müller et al., 2011). Por conta disso, são necessários procedimentos específicos que permitam acompanhar a evolução do crescimento do extrato arbóreo para determinar as prescrições de manejo que serão adotadas.

Sobre este aspecto, dois métodos já utilizados para modelar a produção de madeira nestes sistemas são os modelos em nível de povoamento (Salles et al., 2012; Oliveira Neto et al., 2013) e a modelagem da distribuição diamétrica (Lopes, 2007; Binoti et al., 2012), a qual pode ser associada a modelos de afilamento de fuste para obtenção de multiprodutos, como madeira para carvão e serraria simultaneamente (Souza, 2005; Müller et al., 2011). Com estas metodologias, a quantificação do componente arbóreo será mais precisa e dará maior segurança na definição do tempo de corte e da destinação do uso da madeira, a fim de maximizar os rendimentos.

Em seguida, é importante proceder uma análise de sensibilidade, para se observar o efeito na viabilidade do SAF frente a diferentes situações de mercado e produtividade. Tradicionalmente, esta análise tem sido aplicada simulando diferentes cenários de preço, custo e produtividade dos produtos comercializados sobre diferentes taxas de juros (Oliveira et al., 2000; Dubè et al., 2002; Santos \& Paiva , 2002; Souza et al., 2007; Müller et al., 2011; Faria, 2013). Com isso, ao alterar o valor de uma dessas variáveis para uma determinada cultura, ao mesmo tempo em que se mantém as demais variáveis fixas, pode-se avaliar o impacto que esta cultura causa nos indicadores econômicos. Ainda, se este processo for realizado para todas as culturas, será possível identificar quais componentes do SAF seriam mais afetados pelas variações.

Em uma análise mais robusta, Bentes-Gama et al. (2005) utilizaram procedimentos computacionais para simular variações de $\pm 20 \%$ das receitas e custos, para avaliar o efeito sobre os rendimentos. Esta simulação foi feita pelo método de Monte Carlo, através da qual se permitiu obter 10.000 cenários distintos. Este método se baseia na geração de valores aleatórios para a variável de interesse repetidas vezes a partir de uma função de densidade de probabilidade definida e, a cada iteração, estes valores são utilizados para calcular os indicadores econômicos (Platon \& Constantinescu, 2014). Após n-iterações, é possível verificar qual o valor médio destes indicadores e qual a probabilidade para eles atingirem um dado valor. Dessa forma, este método permite criar cenários de variação de preços, taxas de juros ou produtividade para estudar como eles influenciam a viabilidade do projeto e antecipar decisões no caso de estas variações virem a ocorrer. Cabe destacar que é necessário uma pesquisa prévia para saber qual seria a melhor função de probabilidade para a variável simulada, de forma a conferir validade aos resultados. No entanto, estudos utilizando a função triangular são encontrados com frequência (Gobbi, 2000; Coelho Júnior et al., 2008; Silva et al., 2012; Souza, 2013).

Assim, a partir destas análises, quanto mais sensível for a cultura ou mais influente ela for na rentabilidade do projeto, mais atenção ela exigirá do manejador com relação aos tratos culturais e ao mercado. Caso contrário, ela poderá colocar em risco a viabilidade econômica do sistema como um todo, seja por uma variação nos preços ou pela redução da produtividade.

Porém, quando o objetivo do SAF é o suprimento de algum serviço ambiental, como sombreamento ou quebra ventos, é possível estimar essas receitas por meio das despesas que deixarão de ocorrer a partir do momento que o sistema se estabelecer (Torquebiau \& Penot, 2006). Assim, desde que se tenha registro das despesas médias anuais com determinado problema, estas se transformarão em receitas à medida que o problema for solucionado.

Este mesmo princípio também serviria para o caso de SAFs para produção de bens, como cercas vivas e adubação verde. Neste caso, calcular-se-iam as receitas 
com base nos custos que se teria na aquisição dos mourões ou de fertilizantes. Neste último caso, cabe destacar a necessidade de se conhecer o potencial de fornecimento dos nutrientes das espécies a serem implantadas, a fim de suprir as exigências das demais culturas em substituição aos fertilizantes convencionais (Mafra et al., 1998; Arco-Verde et al., 2008).

Outra maneira de usufruir dos benefícios econômicos dos SAFs seria a sua implantação em áreas com necessidades de adequação ambiental (Oliveira Neto et al., 2012). Neste caso, o sistema pode ser utilizado não somente para amortizar as despesas com a recuperação de áreas, mas também para geração de renda (Santos et al., 2002; Rodrigues et al., 2007, 2008; Faria, 2013).

Além disso, o enriquecimento de florestas pode ser uma alternativa interessante para evitar a prática de desmatamento para produção agrícola. A exemplo do trabalho de Costa et al. (2013), ao simular plantios de cupuaçuzeiro em capoeiras na Amazônia por dez anos, foi verificado que o rendimento com a cultura sozinha não ultrapassou o custo de oportunidade do uso convencional de corte e queima praticado na região. Porém, os autores verificaram que este sistema gerou uma renda estável após cinco anos e que ele poderia ser considerado como uso da terra complementar a outros SAFs no favorecimento da agricultura familiar. Neste caso, o custo de oportunidade de não se utilizar a área de floresta pode ser superado pelos rendimentos do SAF, o que garantiria não somente a sustentação econômica dos produtores, mas também a manutenção dos recusos naturais.

\section{Análise econômica comparativa}

No que tange a experimentos piloto ou para fins de pesquisa, a análise econômica tem sido realizada ao final do período da cultura de maior ciclo ou de um tempo preestipulado após a implantação do sistema, a fim de averiguar o seu potencial de rendimento.

Para o caso de projetos em que não serão alterados o desenho ou as espécies no decorrer do tempo, é interessante que se faça uma análise comparativa da produção das mesmas espécies em monocultivo instaladas em parcelas de controle. Nestas, podem ser instaladas as culturas em espaçamento similar ao do SAF (Bentes-Gama et al., 2005), as quais não sofreriam o efeito da interação do consórcio, mas somente do arranjo espacial. Ou ainda, pode-se também adotar nas parcelas controle o espaçamento convencional das espécies em monocultivo, se a intenção for conhecer a os reais valores de produtividade para o local.

As comparações entre tratamentos de cada espécie deverão ser feitas em termos de produtividade, isto é, quantidade de produtos por unidade de área que a espécie ocupa (área útil). Caso contrário, se considerar a área total da parcela, a comparação não seria justa, pois no SAF cada espécie ocupará apenas uma fração do espaço da parcela e causaria subestimação da produtividade.

A comparação econômica, portanto, deverá ser feita somando-se as receitas e custos referentes aos produtos gerados para se obter a produtividade total anual (rendimento área ${ }^{-1} \mathrm{ano}^{-1}$ ) dos tratamentos a serem comparados (SAF versus monocultivo) e, principalmente, através dos indicadores econômicos descritos anteriormente.

Além disso, pode ser feita a simulação dos rendimentos como se na área fosse cultivada uma única espécie, de preferência aquela mais lucrativa. Ou ainda, se for o caso de avaliar um sistema já instalado, com dados sobre sua produtividade, pode ser feita a comparação com as mesmas espécies cultivadas em sistema convencional, com informações de produtividade adequados para a região. Dessa forma, estes rendimentos simulados poderão servir como alternativa de investimento, da mesma forma que ocorre com o arrendamento de terras ou inventimentos bancários, e ajudarão os investidores a decidirem sobre o melhor sistema a ser adotado.

\section{Considerações finais}

Este trabalho apresenta um conjunto de procedimentos e referências capazes de auxiliar pesquisadores e técnicos extencionistas na avaliação econômica de experimentos e projetos de sistemas agroflorestais sem, contudo, esgotar o assunto sobre viabilidade de SAF existentes na literatura. Por conta disso, cabe destacar que esta revisão se restringe à questão econômica e financeira, e que a viabilidade completa do sistema deve abranger a questão social e técnica, além de estar sujeita à legislação vigente, qundo se trata de propostas para áreas protegidas.

Verifica-se também que mesmo após décadas de pesquisas sobre agrossilvicultura, existem muitas dúvidas que necessitam ser respondidas e contempladas, principalmente no que tange à valoração dos demais possíveis benefícios dos SAFs. Entretanto, tais lacunas não devem constituir por si só impedimentos para a sua adoção, por existirem métodos de avaliação que podem contornar as incertezas. 
Além disso, torna-se necessária a promoção dos benefícios ambientais (externalidades) pelas partes envolvidas, a fim de ganhar o reconhecimento da população e órgãos públicos. Pela divulgação e apoio governamental, novas oportunidades de mercado poderão ser criadas e mais valorizado serão seus produtos, de forma a internalizar estes benefícios gerados no processo produtivo.

Por fim, a escolha dos métodos de análise econômica ficará à cargo do analista do projeto, que definirá aqueles que mais se ajustam à realidade das partes envolvidas, tendo em mente que quantias maiores de investimento exigirão análises mais detalhadas.

\section{Agradecimentos}

Este trabalho foi realizado graças ao apoio financeiro concedido pelo Conselho Nacional de Desenvolvimento Científico e Tecnológico (CNPq).

\section{Referências}

Alavalapati, J. R. R. et al. Agroforestry development: an environmental economic perspective. Agroforestry Systems, v. 61, p. 299-310, 2004. DOI: 10.1023/B:AGFO.0000029006.64395.72.

Alves, E. P. et al. Economic analisys of a coffee-banana system of a family-based agriculture at the atlantic forest zone, Brazil. Ciência e Agrotectologia, v. 39, n. 3, p. 232-239, 2015. DOI: 10.1590/S141370542015000300004 .

Arco-Verde, M. F. et al. Aporte de nutrientes e produtividade de espécies arbóreas e de cultivos agrícolas em sistemas agroflorestais na Amazônia. Floresta, v. 39, n. 1, p. 11-22, 2008. DOI: 10.5380/ rf.v39i1.13721.

Batish, D. R. et al. Ecological basis of agroforestry. Boca Raton: CRC Press, 2008. 382 p.

Bentes-Gama, M. de M. et al. Análise econômica de sistemas agroflorestais na Amazônia Ocidental, Machadinho D'Oeste-RO. Revista Árvore, v. 29, n. 3, p. 401-411, 2005. DOI: 10.1590/S010067622005000300007.

Binoti, D. H. B. et al. Descrição da distribuição diamétrica de sistemas agrossilvipastoris utilizando as funções Weibull e Hiperbólica. Revista Árvore, v. 36, n. 2, p. 349-356, 2012. DOI: 10.1590/S010067622012000200016.

Campos, J. C. C. \& Leite, H. G. Mensuração florestal: perguntas e respostas. 4. ed. Viçosa, MG: Ed. da UFV, 2013. 605 p.

Cardoso, I. M. et al. Continual learning for agroforestry system design: university, NGO and farmer partnership in Minas Gerais, Brazil. Agricultural Systems, v. 69, n. 3, p. 235-257, 2001. DOI: 10.1016/S0308-521X(01)00028-2.

Coelho Júnior, L. M. et al. Análise de investimento de um sistema agroflorestal sob situação de risco. Cerne, v. 14, n. 4, p. 368-378, 2008.
Costa, R. C. da. et al. Pagamentos por serviços ambientais, custos de oportunidade e a transição para usos da terra alternativos: o caso de agricultores familiares no Nordeste Paraense. Sustentabilidade em Debate, v. 4, n. 1, p. 99-116, 2013. DOI: 10.18472/SustDeb. v4n1.2013.9202.

Dubè, F. et al. Avaliação econômica de um sistema agroflorestal com Eucalyptus sp. no noroeste de Minas Gerais: o caso da Companhia Mineira de Metais. Revista Árvore, v. 42, n. 4, p. 437-443, 2000.

Dubè F. et al. A simulation model for evaluating technical and economic aspects of an industrial eucalyptus-based agroforestry system in Minas Gerais, Brazil. Agroforestry Systems, v. 55, n. 1, p. 73-80, 2002. DOI: 10.1023/A:1020240107370.

Faria, C. M. A. de. Integração lavoura, pecuária e floresta como alternativa para recuperação de pastagens degradadas na região de Bambuí-MG. 2013. 105 f. Tese (Doutorado em Fitotecnia) Universidade Federal de Viçosa, Viçosa, MG.

García-Barrios, L. \& Ong, C. K. Ecological interactions, management lessons and design tools in tropical agroforestry systems. Agroforestry Systems, v. 61, n. 1, p. 221-236, 2004. DOI: 10.1023/B:AGFO.0000029001.81701.f0.

Gobbi, J. A. Is biodiversity-friendly coffee financially viable? An analysis of five different coffee production systems in western El Salvador. Ecological Economics. v. 33, n. 2, p. 267-281. 2000. DOI: 10.1016/S0921-8009(99)00147-0.

Lopes, P. F. Modelo de distribuição de diâmetros para clones de eucalipto em sistema agroflorestal. 2007. 32 f. Dissertação (Mestrado em Ciência Florestal) - Universidade Federal de Viçosa, Viçosa, MG.

Lyngbæk, A. E. et al. Productivity and profitability of multistrata organic versus conventional coffee farms in Costa Rica. Agroforestry Systems, v. 53, n. 2, p. 205-213. 2001. DOI: 10.1023/A:1013332722014.

Mafra, A. L. et al. Adição de nutrientes ao solo em sistema agroflorestal do tipo "cultivo em aléias" e em cerrado na região de Botucatu, SP. Scientia Forestalis, n. 54, p. 41-54, 1998.

Müller, D. M. et al. Economic analysis of an agrossilvipastoral systems for a mountainous area in Zona da Mata Mineira, Brazil. Pesquisa Agropecuária Brasileira, v. 46, n. 10, p. 1148-1153, 2011. DOI: $10.1590 / \mathrm{S} 0100-204 X 2011001000005$.

Müller, M. D. et al. Estimativa de acúmulo de biomassa e carbono em sistema agrossilvipastoril na Zona da Mata Mineira. Pesquisa Florestal Brasileira, n. 60, p. 11-17, 2009. DOI: 10.4336/2009. pfb.60.11.

Nair, P. K. R. An introduction to agroforestry. Dordrecht: Kluwer Academic, 1993. 499 p.

Nair, P. K. R. Directions in tropical agroforestry research: past, present, and future. Agroforestry Systems, v. 38, n. 1, p. 223-245, 1997. DOI: 10.1023/A:1005943729654.

Oliveira, A. D. de et al. Análise econômica de um sistema agro-silvopastoril com eucalipto implantado em região de cerrado. Ciência Florestal, v. 10, n. 1, p. 1-19, 2000.

Oliveira Neto, S. N. de et al. Sistemas agroflorestais para adequação ambiental de propriedades rurais. Informe Agropecuário, v. 33, n. 271, p. 70-77, 2012. 
Oliveira Neto, S. N. de et al. Sistema agrossilvipastoril: integração lavoura, pecuária e floresta. Viçosa, MG: Sociedade de Investigações Florestais, 2010. 190 p.

Oliveira Neto, S. N. de et al. Tree modeling and economic evaluation of agroforestry systems in Southeastern Brazil. Silva Lusitana, v. 21, n. 1, p. $43-60,2013$.

Platon, P. \& Constantinescu, A. Monte Carlo Method in risk analysis for investment projects. Procedia Economics and Finance, v. 15, p. 393-400, 2014. DOI: 10.1016/S2212-5671(14)00463-8.

Raintree, J. B. An introduction to agroforestry diagnostics and design. Nairobi: International Council for Research in Agroforestry (ICRAF), 1986. 56 p.

Rao, M. R. et al. Biophysical interactions in tropical agroforestry systems. Agroforestry Systems, v. 38, n. 1, p. 3-50, 1997. DOI: 10.1023/A:1005971525590.

Rezende, J. L. P. de \& Oliveira, J. L. P. de. Análise econômica e social de projetos florestais. 3. ed. Viçosa, MG: Ed. da UFV, 2013. $385 \mathrm{p}$.

Rodrigues, E. R. et al. Avaliação econômica de sistemas agroflorestais implantados para recuperação de reserva legal no Pontal do Paranapanema, São Paulo. Revista Árvore, v. 31, n. 5, p. 941-948, 2007. DOI: $10.1590 / \mathrm{S} 0100-67622007000500018$.

Rodrigues, E. R. et al. O uso do sistema agroflorestal taungya na restauração de reservas legais: indicadores econômicos. Floresta, v. 38, n. 3, p. 517-525, 2008. DOI: 10.5380/rf.v38i3.12420.

Salles, T. T. et al. Modelo de Clutter na modelagem de crescimento e produção de eucalipto em sistemas de integração lavoura-pecuária-floresta. Pesquisa Agropecuária Brasileira, v. 47, n. 2, p. 253-260, 2012. DOI: 10.1590/S0100-204X2012000200014.

Santos, M. J. C. dos et al. Avaliação econômica de quatro modelos agroflorestais em áreas degradadas por pastagens na Amazônia Ocidental. Scientia Forestalis, n. 62, p. 48-61, 2002.

Santos, M. J. C. dos \& Paiva, S. N. de. Os sistemas agroflorestais como alternativa econômica em pequenas propriedades rurais: estudo de caso. Ciência Florestal, v. 12, n. 1, p. 135-141, 2002.
Silva, M. L. da \& Fontes, A. A. Discussão sobre os critérios de avaliação econômica: valor presente líquido (VPL), valor anual equivalente (VAE) e valor esperado da terra (VET). Revista Árvore, v. 29, n. 6, p. 931-936, 2005. DOI: 10.1590/S010067622005000600012 .

Silva, C. P. de C. et al. Economic analysis of agroforestry systems with candeia. Cerne, v. 18, n. 4, p. 585-594, 2012. DOI: 10.1590/ S0104-77602012000400008.

Silva, M. L. da et al. Economia Florestal. 2. ed. ,Viçosa, MG: Ed. da UFV, 2005.178 p.

Souza, B. R. de. Determinação do risco financeiro em sistemas agroflorestais utilizando o método Monte Carlo. 2013. $60 \mathrm{f}$. Dissertação (Mestrado em Ciências Florestais) - Universidade de Brasília, DF.

Souza, H. N. de et al. Strategies and economics of farming systems with coffee in the Atlantic Rainforest Biome. Agroforest Systems, v. 84 , n. 2 , p. $227-242$. 2012. DOI: 10.1007/s10457-011-9452-x.

Souza, N. D. Crescimento, produção e análise econômica de povoamentos clonais de Eucalyptus $\mathrm{sp}$. em sistemas agroflorestais. 2005. 203 f. Tese (Doutorado em Engenharia Florestal) - Universidade Federal de Lavras, Lavras.

Souza, N. D. et al. Viabilidade econômica de um sistema agroflorestal. Cerne, v. 13, n. 1, p. 96-106, 2007.

Thompson, D. \& George, B. Financial and economic evaluation of agroforestry. In: Nuberg, I. et al. Agroforestry for natural resource management. Collingwood: CSIRO Publishing, 2009. p. 281-330.

Torquebiau, E. \& Penot, A. E. Ecology versus economics in tropical multistrata agroforests. In: Kumar, B. M. \& Nair, P. K. R. Tropical homegardens: a time-tested example of sustainable agroforestry. Netherlands: Springer, 2006. p. 269-282.

Trindade, C. et al. Ferramentas da qualidade: aplicação na atividade florestal. 2. ed. Viçosa, MG: Ed. da UFV, 2007. 159 p.

Vivan, J. L. Manual de diagnóstico e desenho de sistemas agroflorestais: manual de campo para extensionistas. Porto Alegre: EMATER, 2000. 43 p.

Wunder, S. et al. Pagamentos por serviços ambientais: perspectivas para a Amazônia legal. 2. ed. Brasília, DF: Ministério do Meio Ambiente, 2009. 144 p. 